\title{
Effects of a combination of scapular stabilization and thoracic extension exercises for office workers with forward head posture on the craniovertebral angle, respiration, pain, and disability: A randomized-controlled trial
}

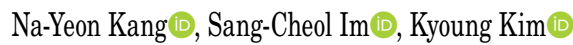 \\ Department of Physical Therapy, Daegu University, College of Rehabilitation Science, Jillyang-eup, Gyeongsan, Republic of Korea
}

Received: April 18, 2020 Accepted: June 23, 2020 Published online: September 01, 2021

\begin{abstract}
Objectives: This study aims to investigate how exercise programs not directly applied to the cervical spine affect office workers with forward head posture (FHP).

Patients and methods: Between March 2018 and June 2018, a total of 32 office workers with FHP (13 males, 19 females; mean age 36.63 years; range, 23 to 57 years) were randomized either to experimental $(n=16)$ or control groups $(n=16)$. Scapular stabilization and thoracic extension exercises were applied to the experimental group and cervical stabilization and stretching exercises to the control group. The results of the pre-intervention and after six weeks measurement of the craniovertebral angle (CVA), respiration, pain, and disability were compared and analyzed.

Results: For intra-group comparison, both groups showed significant differences $(\mathrm{p}<0.05)$ in CVA, forced expiratory volume at 1 sec (FEV1), Visual Analog Scale (VAS), and neck disability index at pre- and post-intervention, while only the experimental group showed a significant difference $(\mathrm{p}<0.05)$ in maximum inspiratory pressure, maximum expiratory pressure, and forced vital capacity. For inter-group comparison, a significant difference $(\mathrm{p}<0.05)$ between FEV1 and VAS was observed.

Conclusion: The combination of scapular stabilization and thoracic extension exercises, not directly applied to the cervical spine, has an effect on improving the posture, respiration, neck pain, and disability in office workers with FHP.
\end{abstract}

Keywords: Cervical spine, exercise, head posture, neck pain.

Approximately $50 \%$ of all individuals experience a clinically important neck pain episode over the course of their lifetime. ${ }^{[1]}$ According to the Global Burden of Disease 2010 Study, neck pain is ranked fourth in terms of disability following back pain, depression, and joint pain; ${ }^{[2]}$ however, the physical, psychological, and socioeconomic impact of neck pain is underestimated. ${ }^{[3]}$ Individuals living in the modern world spend more time on the computer in a day, which results in poor posture, leading to neck pain. ${ }^{[4]}$ Musculoskeletal disorders associated with the neck and upper limbs are very common among those working on computers, and the working hours on the computer is also associated with the prevalence of musculoskeletal disorders. ${ }^{[5]}$ When the cervical spine is constantly put under pressure by working for long hours in front of the computer, a transformation occurs in the spinal curves, leading to degenerative changes in joints, straight cervical spine, and forward head posture (FHP). ${ }^{[6]}$

Corresponding author: Kyoung Kim, PhD. Department of Physical Therapy, College of Rehabilitation Science, Daegu University, 201 Daegudae-ro, Jillyang-eup, Gyeongsan 38453, Republic of Korea. e-mail: kykim257@hanmail.net 
Forward head posture is characterized by hyperextension of the upper cervical spine (C1-C3) and flexion of the lower cervical spine (C4-C7); cranial rotation angle increases, and craniovertebral angle (CVA) decreases. ${ }^{[7]}$ Due to the structural characteristics, round shoulder posture (RSP) occurs with FHP and the back is curved, typifying a stooped posture with a protrusion of the acromion of the shoulder joint relative to the centerline of gravity of the body and a lift-up of the scapula. ${ }^{[8]}$ Forward head posture and RSP are associated with musculoskeletal disorders of the neck and body, such as upper crossed syndrome, ${ }^{[9]}$ and cause pain in the head, jaw, neck, back, shoulders, and arms due to muscular imbalance. ${ }^{[10]}$ Pain itself and the relationship between poor posture and respiratory function are considered important. ${ }^{[1]}$ Forward head posture abnormally changes the structure of the cervical and thoracic spine, which can cause further changes in the thorax and respiratory function. ${ }^{[12]}$ Furthermore, disorders of the cervical and thoracic spine muscles are related with respiratory function disorders. ${ }^{[13]}$ Among those with FHP, myotonia increases in the sternocleidomastoid muscle and, then, the thorax moves up. Therefore, mobility around the thoracolumbar area decreases, and the ventilatory function of the diaphragm reduces. Accordingly, the respiratory function decreases. ${ }^{[14]}$

In a recent review, therapeutic exercise improved CVA and neck pain of participants with FHP. ${ }^{[15]}$ Also, there are many studies regarding neck pain and functional disorders and improving posture through different exercise programs, such as extension exercise and muscle strengthening exercise ${ }^{[16]}$ and deep cervical flexor training of the cervical spine. ${ }^{[17]}$ To manage FHP, indirect treatment instead of direct treatment of the neck can be used, which is the basis for the concept of regional interdependence, i.e., the cause of pain becomes the cause of damage to other body parts. ${ }^{[18]}$ Therefore, not treating the damaged part, but indirectly treating the area of cause can alleviate the symptoms. ${ }^{[19]}$ A previous research recommended scapular stabilization exercise (SSE) as a recovery treatment for imbalanced scapular muscles caused by FHP and RSP. ${ }^{[20]}$ A biodynamic relationship between the cervical and thoracic spine is associated with exercise, which is an important factor causing neck pain. ${ }^{[21]}$ Therefore, many clinicians pay attention to the thoracic spine of patients with neck pain ${ }^{[22]}$ and recommend thoracic extension exercise (TEE). ${ }^{[23]}$

Many studies have been conducted wherein the neck of patients with FHP was directly affected, but the effects of exercise not directly affecting the neck have not been well understood, and there is a lack of research on the effect on respiration. In the present study, we hypothesized that the combination of SSE and TEE would be effective in improving CVA, respiration, neck pain, and Neck Disability Index (NDI) in patients with FHP. We, therefore, aimed to examine the effects of a combination of SSE and TEE to improve CVA, respiration, neck pain, and NDI in office workers with FHP and to compare the effects of exercise directly applied to the cervical spine and exercise for the thoracic spine and scapula not directly applied to the cervical spine.

\section{PATIENTS AND METHODS}

This prospective, randomized-controlled study included office workers with FHP aged between 20 and 60 years who were working at two elementary schools located in Ulsan, Republic of Korea between March 2018 and June 2018. The selection criterion of the participants was FHP and a score of $\geq 4$ for Visual Analog Scale (VAS). Forward head posture was evaluated using photogrammetry. Participants with centerline of external auditory meatus deviated from the centerline of scapula acromion $>2.5 \mathrm{~cm}^{[24]}$ and CVA $<53^{\circ[25]}$ were included in this study. Exclusion criteria included a serious pathological condition such as a tumor, whiplash injury within the past three months, history of cervical and thoracic spine surgery, and neurological signs compatible with nerve root pressure. Finally, a total of 32 office workers with FHP (13 males, 19 females; mean age 36.63 years; range, 23 to 57 years) were included in the study. A written informed consent was obtained from each participant. The study protocol was approved by the Institutional Review Board of Daegu University (1040621-201801-HR-009-02). The study was conducted in accordance with the principles of the Declaration of Helsinki.

\section{Interventions}

All participants underwent a physical examination, and their demographic data were collected. Using the sealed envelope method, participants drew cards on which exercise names were written and were randomly assigned into either the experimental $(\mathrm{n}=16)$ or control group $(n=16)$. The SSE and TEE were applied to the experimental group, whereas only cervical stabilization exercises (CSE) and stretching exercises (SE) were applied to the control group. Both groups performed exercises for $40 \mathrm{~min}$ per day, thrice per week for a total of six weeks. The CVA, respiratory pressure, respiratory function, VAS, and NDI measurement at pre- and 
post-intervention were compared and analyzed. All the interventions were supervised and managed by a single physiotherapist with $>5$ years of clinical experience in musculoskeletal physical therapy.

\section{SSE and TEE}

The $\mathrm{SSE}^{[26]}$ and TEE, ${ }^{[23]}$ used in previous studies, were revised and supplemented to be used in this study.

The SSE was comprised of four exercise programs. The participants sat on the knees in $90^{\circ}$ flexion position, and a Swiss ball was propped up between the chest and stomach. Looking from the side, the earlobe, acromion of scapula, and pelvis made a straight line.

A. Scapula retraction exercise: While retracting both the scapula, raise both the arms backward.

B. Scapula mobilization exercise: With thumbs up, raise both the arms sideways making a straight line with the shoulders.

C. Scapula dynamic stabilization exercise I: Raise one arm beside the ear and push out the other arm behind the back. Do the same for the opposite side.
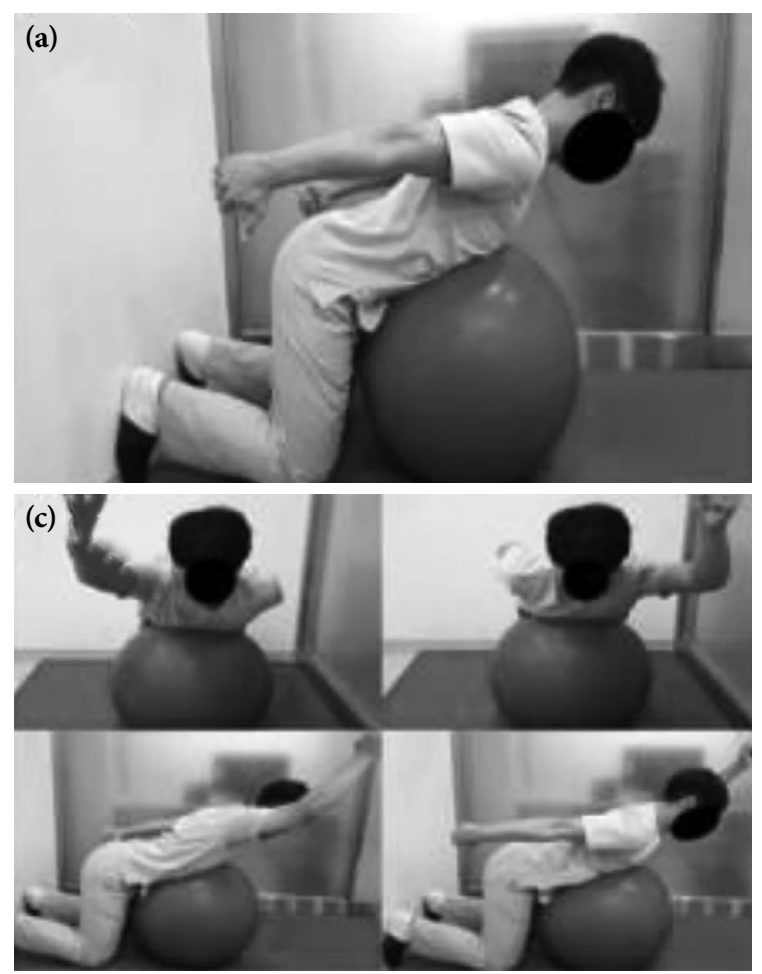

Figure 1. Scapula stabilization exercise program.
D. Scapula dynamic stabilization exercise II: Raise both the arms beside the ears and then push them down bending and maintaining elbows at $90^{\circ}$. Raise both the arms beside the ears again and put them down.

Each exercise was performed with two sets of 15 reps, $10 \mathrm{sec}$ per rep. After four weeks, the exercise intensity was increased by adding weight with dumbbells (Figure 1).

The TEE was comprised of three exercise programs as follows:

A. TEE I: Locate the restricted thoracic spinal segment on a foam roller and lie on it with the knees flexed. Cross both the hands on the chest and slightly lift the buttocks from the floor. Then, slowly roll the foam roller up and down the thoracic spinal segment.

B. TEE II: Sitting with knees flexed, place a Swiss ball in front. Then, push the ball forward to a distance with both hands on it.

C. TEE III: In the prone position, repeat lifting up and putting down the upper body while supporting the body with both the elbows.
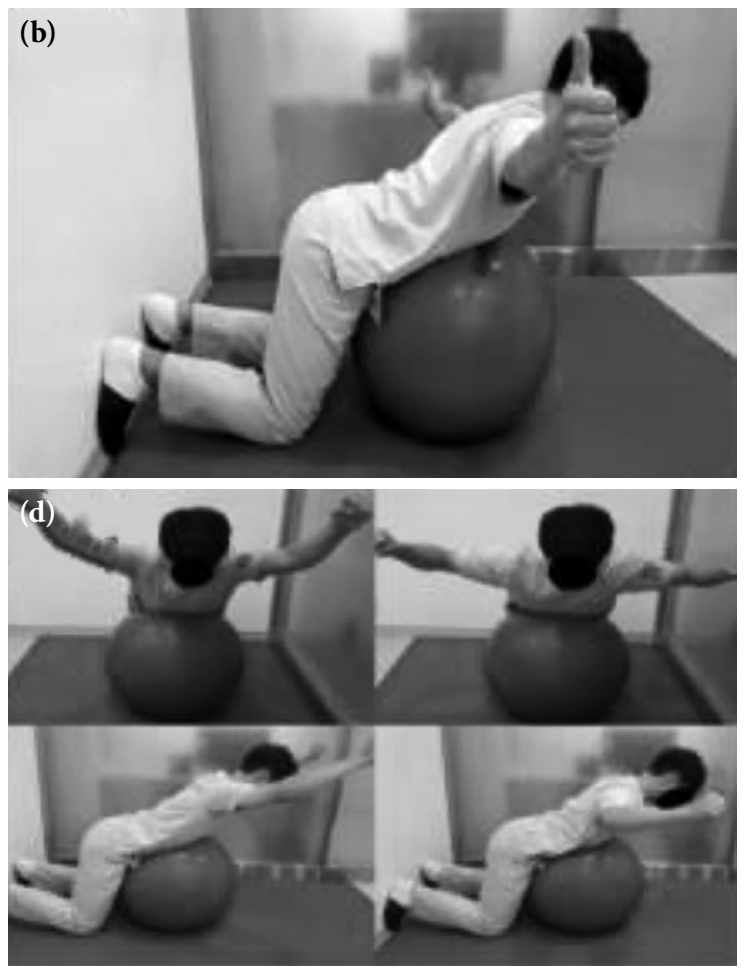

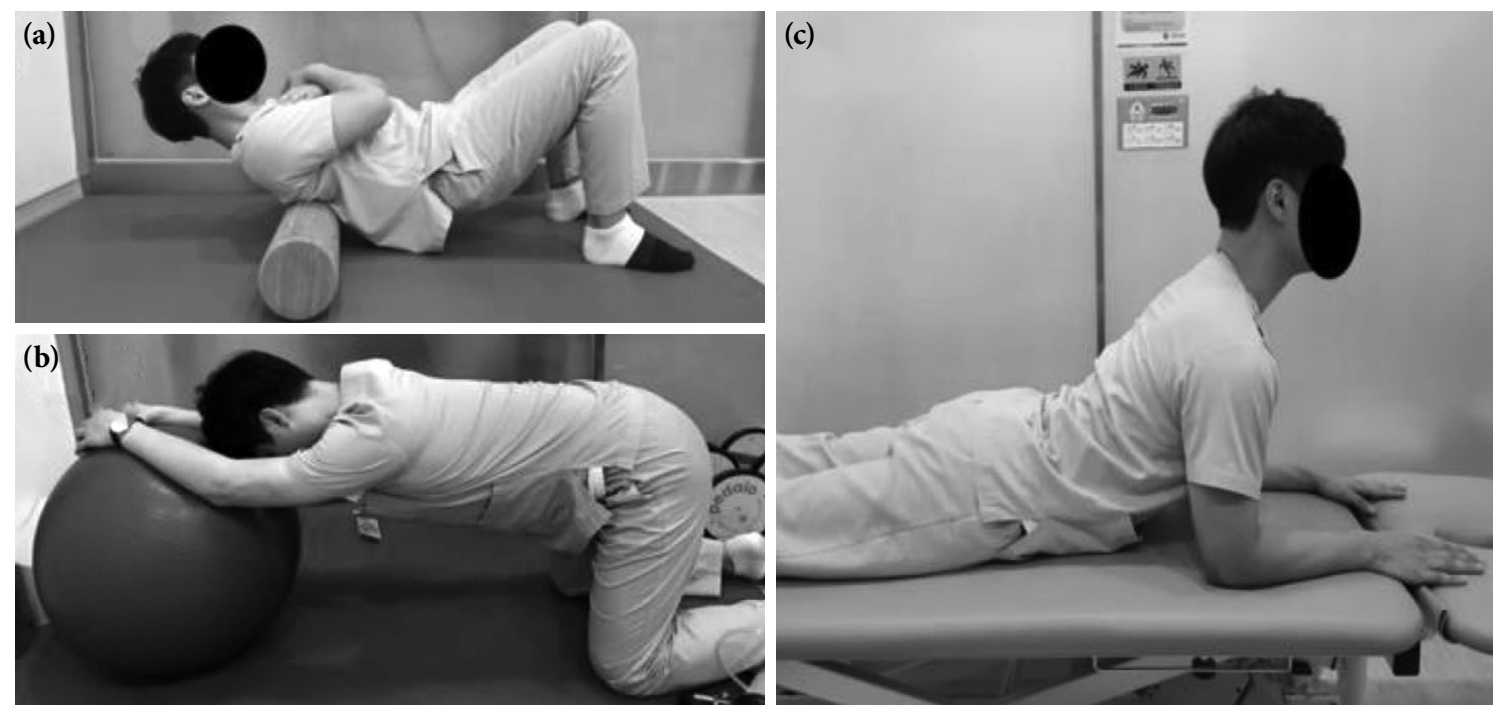

Figure 2. Thoracic extension exercise program.

Each exercise was performed with two sets of 15 reps, 10 sec per rep (Figure 2).

\section{Cervical stabilization exercises and stretching exercises}

The $\mathrm{CSE}^{[27]}$ and SE, ${ }^{[16]}$ used in previous studies, were revised and supplemented to be used in this study.

The CSE is a deep cervical flexor muscle exercise and was performed using stabilizer pressure biofeedback (Chattanooga, Hixson, TN, USA), which is an air injection pressure regulator. The participants lied down straight staring at the ceiling with knees bent, and the pressure regulator was placed underneath the head. Pulling the jaw to press the regulator, they checked the pressure figures on the gauge board. They remained at the respective goal level for $10 \mathrm{sec}$ and

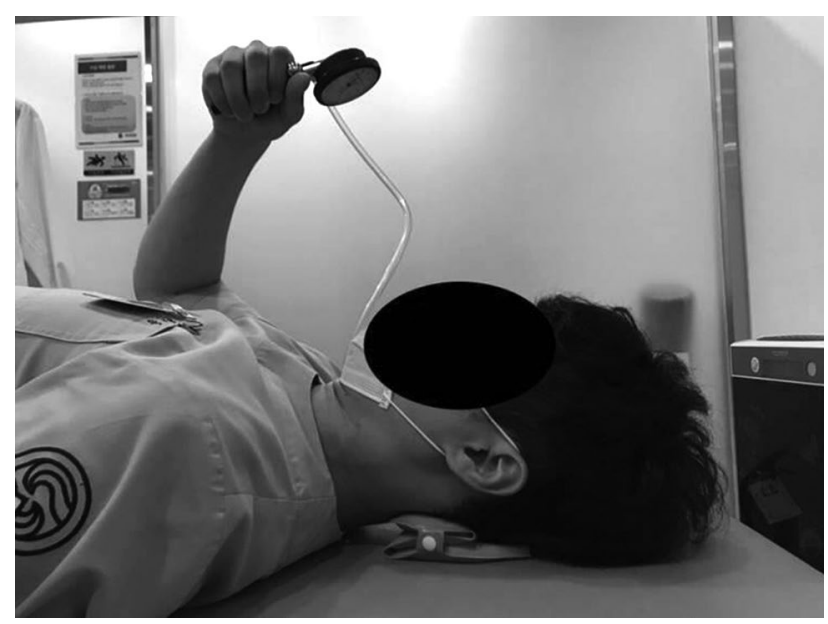

Figure 3. Cervical stabilization exercise. then took a 5-sec break. The goal level was defined as one at which participants can constantly hold for $5 \mathrm{sec}$ without contracting or using neck flexion muscle on the surface. They performed two sets of 10 reps per set and had a 1-min inter-set rest (Figure 3).

The SE was comprised of six motions by which the cervical spine and muscles around the shoulder joint could stretch. After holding each motion for $20 \mathrm{sec}$, the participants took a 5-sec rest. Cervical SE was performed on the left and right sides. Performing six motions once was a set, and eight sets a day were performed.

\section{Outcome measures}

As a primary outcome, CVA, respiratory pressure (PImax), and respiratory function were measured. The CVA was measured using the Adobe Photoshop CS2 software (Adobe Systems Inc., CA, USA) after taking a picture with a digital camera. ${ }^{[28]}$ The digital camera was installed 104 inches away from the participants and 33 inches away from the floor. The participants stood straight with both arms comfortably beside the body, and they were supposed to look at their own eyes reflected in the front mirror. Making the maximum flexion of the head and the maximum extension again, they repeated the connecting movement thrice and paused at the most comfortable position for taking a picture. The CVA is the angle made with the lines of a horizontal line of $\mathrm{C} 7$ and a line from tragus to spinous process of C7. ${ }^{[29]}$ After pictures were taken thrice, the average of these measurements was calculated. 
The respiratory pressure test was performed in a sitting position using the MicroRPM (Care Fusion, Basingstoke, UK), and maximum inspiratory pressure (MIP) and maximum expiratory pressure (MEP) were measured. Before measurement, several training sessions were provided so that the participants would be aware of the measurement method. The average of three measurements was calculated. In the respiratory function test, forced vital capacity (FVC), forced expiratory volume at $1 \mathrm{sec}$ (FEV1), and the ratio of FEV1/FVC were measured using the CardioTouch 3000 (Bionet, Seoul, Korea). The average of three measurements was calculated.

As a secondary outcome, the VAS and NDI were measured. The intensity of participants' subjective neck pain was measured using the VAS. The intraclass correlation coefficient (ICC) of VAS measurement for neck pain is 0.97 and is a highly reliable measurement method. ${ }^{[30]}$ Using NDI, we evaluated how restrictive everyday life is due to neck pain. The NDI is a widely used and reliable measure method with an ICC of $0.98 .^{[31]}$

\section{Statistical analysis}

Power analysis and sample size calculation were performed using the $G^{*}$ Power version 3.1.9.4 software (Heinrich-Heine-Universität Düsseldorf, Düsseldorf, Germany). An effect size of 0.91 was set up for the pain variations, as per the previous study which had the same research design as the present one and compared the effects of isometric exercise of cervical spine extensor. ${ }^{[32]}$ The Cohen's $d$ formula was used for effect size equivalent to the effects noticed for intraand inter-group comparisons of the two groups. An effect size d of 0.2 represents a small, 0.5 a medium, and 0.8 a large effect size. The sample size was calculated using an effect size $d$ of $0.91,80 \%$ of power (1- $\beta$ error probability), and 0.05 of significance level.
Therefore, a total of 32 participants were needed to be included in this study.

Statistical analysis was performed using the IBM SPSS for Windows version 22.0 software (IBM Corp., Armonk, NY, USA). Descriptive data were presented in mean \pm standard deviation (SD), median (min$\max$ ) or number and frequency, where applicable. A normality test was performed using the ShapiroWilk test. For homogeneity test of the experimental and control groups, independent sample t-test and chi-square test were conducted. Matching sample t-test was used to compare pre- and post-intervention results of measurement within the two groups. An independent t-test was used to confirm the curative effect between the two groups. A $p$ value of $<0.05$ was considered statistically significant.

\section{RESULTS}

No significant difference was observed between the two groups in terms of baseline demographic characteristics ( $p>0.05$; Table 1$)$.

Table 2 shows a comparison of the primary outcomes of the two groups. Both groups had a significant difference $(\mathrm{p}<0.05)$ in CVA in intra-group comparison and a strong effect size $(\mathrm{d}=1.2,0.8)$. For MIP, MEP, and FVC, a significant difference was observed only in the experimental group in intra-group comparison $(\mathrm{p}<0.05)$ with an average effect size ( $d=0.6$ to 0.7$)$. The FEV1 showed a significant difference in both groups in intra-group comparison $(\mathrm{p}<0.05)$ with a strong and average effect size in each $(\mathrm{d}=1.1,0.7)$. For inter-group comparison, a significant difference $(\mathrm{p}<0.05)$ was observed with an average effect size $(\mathrm{d}=0.7)$.

Table 3 shows a comparison of the secondary outcomes of the two groups. Both groups showed a

\begin{tabular}{|c|c|c|c|c|c|c|c|}
\hline \multicolumn{8}{|c|}{$\begin{array}{l}\text { TABLE } 1 \\
\text { Baseline demographic characteristics of participants }\end{array}$} \\
\hline & \multicolumn{3}{|c|}{ Experimental group $(n=16)$} & \multicolumn{3}{|c|}{ Control group $(\mathrm{n}=16)$} & \multirow[b]{2}{*}{$p^{*}$} \\
\hline & $\mathrm{n}$ & $\%$ & Mean \pm SD & $\mathrm{n}$ & $\%$ & Mean \pm SD & \\
\hline Age (year) & & & $37.5 \pm 10.6$ & & & $35.8 \pm 8.0$ & $0.60 \dagger$ \\
\hline Sex & & & & & & & $0.71 \neq$ \\
\hline Male & 6 & 37.5 & & 7 & 43.7 & & \\
\hline Height $(\mathrm{cm})$ & & & $167.3 \pm 7.1$ & & & $168.6 \pm 9.6$ & $0.66 \dagger$ \\
\hline Weight $(\mathrm{kg})$ & & & $62.3 \pm 9.2$ & & & $64.4 \pm 11.1$ & $0.57 \dagger$ \\
\hline Body mass index $\left(\mathrm{kg} / \mathrm{m}^{2}\right)$ & & & $22.2 \pm 2.4$ & & & $22.5 \pm 2.2$ & $0.71 \dagger$ \\
\hline
\end{tabular}



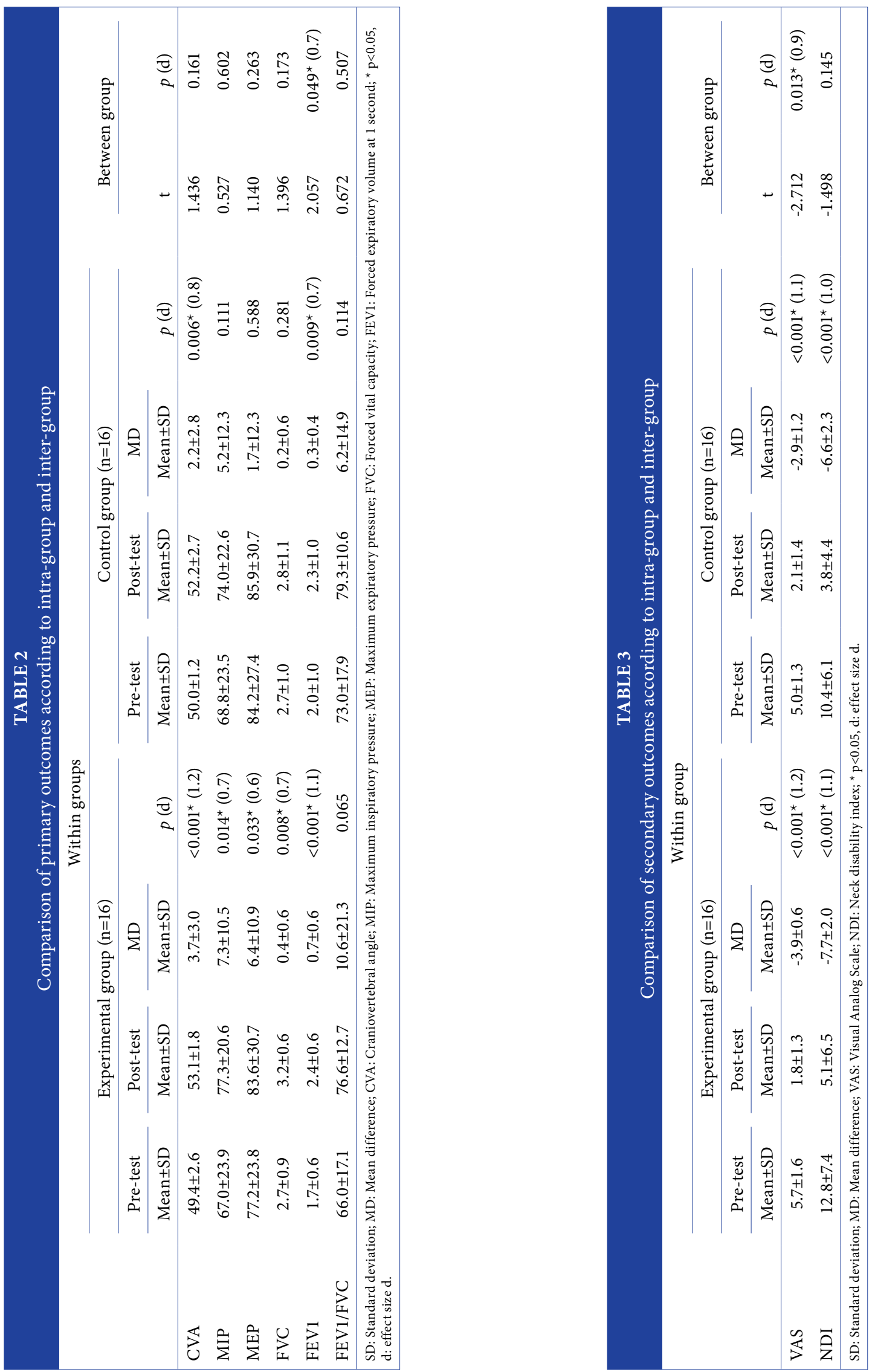
significant difference $(\mathrm{p}<0.05)$ in VAS in intra-group comparison with a strong effect size $(\mathrm{d}=1.2,1.1)$. A significant difference was observed in inter-group comparison $(\mathrm{p}<0.05)$ with a strong effect size $(\mathrm{d}=0.9)$. The NDI showed a significant difference in both groups in intra-group comparison $(\mathrm{p}<0.05)$ with a strong effect size $(\mathrm{d}=1.1,1.0)$.

\section{DISCUSSION}

Neck pain is a part of occupational musculoskeletal disorders and mainly occurs in individuals whose occupations involve working for long hours on computers. ${ }^{[33]}$ Office workers do monotonous and repetitive jobs in an unnatural posture for a long time, have insufficient rest, and are exposed to excessive workload. Particularly, working on computers leads to inappropriate postures than those sitting upright and looking forward. ${ }^{[4]}$ Such inappropriate postures give rise to constant stress to the structure around the neck, leading to FHP, which is characterized by headache and neck pain. ${ }^{[34]}$ In addition, FHP is highly associated with decreased respiratory function. ${ }^{[11,12]}$ Therefore, in this study, we investigated how a combination of SSE and TEE affected CVA, respiration, pain, and NDI in office workers with FHP.

In the present study, the CVA results showed a statistically significant increase at pre- and postintervention in intra-group comparison in both groups $(\mathrm{p}<0.05, \mathrm{~d}=1.2,0.8)$; however, no significant difference was observed in inter-group comparison $(p>0.05)$. A previous study demonstrated that applying stretching and muscle strengthening exercise programs to FHP improved CVA. ${ }^{[29]}$ In another study, applying chest muscle SE using a foam roller as chest exercise, scapular exercise, and chin-in exercise were effective for both FHP and RSP. ${ }^{[35]}$ Furthermore, Shiravi et al. ${ }^{[36]}$ reported that SSE reduced the activity of upper trapezius, which improved the muscle strength and function of FHP and RSP. In our study, a combination of SSE and TEE strengthened the muscles around the thoracic spine and adjusted the thoracic spinal alignment, leading to an increase in CVA. An increase in CVA indicates an improvement in FHP. Accordingly, a combination of SSE and TEE is effective, which is similar to the combination of CSE and SE. In a study by Cho et al.,, ${ }^{[37]}$ mobilization and mobility exercises were applied to the upper body of patients with FHP, and an increase in CVA was reported, which is consistent with our study findings.

The result of respiratory function measurement showed a significant difference only in the experimental group for MIP, MEP, and FVC $(p<0.05, d=0.6$ to 0.7$)$. The FEV1 showed a significant difference in both groups $(\mathrm{p}<0.05, \mathrm{~d}=1.1,0.7)$. For inter-group comparison, a significant difference was observed only in FEV1 $(\mathrm{p}<0.05, \mathrm{~d}=0.7)$, but for other variables, a greater increase was observed in the experimental group. A previous study reported that the abnormal structure of the cervical and thoracic spine caused a movement disorder of the rib cage, which affected the respiratory function and led to a decrease in lung volume and vital capacity and weakening of the respiratory muscles. ${ }^{[38]}$ Another study reported that worse FHP represented lower figures in the respiratory pressure. ${ }^{[13]}$ Therefore, it is considered that a combination of SSE and TEE, used in this study, improves the imbalance of respiratory muscles due to FHP and positively affects the alignment of the cervical and thoracic spine so that the respiratory function is enhanced. A study by Kang et al. ${ }^{[27]}$ showed that SSE activated neck muscles, lowered the trapezius and serratus anterior muscles, and improved FHP, supporting the results of this study. It is considered that a combination of SSE and TEE applied to the thoracic spine in the experimental group is more effective in improving respiratory competence than CSE and SE, which are directly applied to the cervical spine in the control group.

In the current study, the VAS and NDI also showed a statistically significant decrease at pre- and postintervention in both groups $(\mathrm{p}<0.05, \mathrm{~d}=1.1$ to 1.2 ). The primary outcomes of this study showed that both exercise programs showed a significant increase in CVA, leading to improvement in FHP. By improving the inappropriate posture, the cervical spinal alignment was well adjusted, reducing the tension and fatigue of the surface muscles such as the upper trapezius and sternocleidomastoid, consequently relieving the muscle imbalance. Therefore, a decrease in pain seems to positively affect VAS and NDI. McDonnel et al. ${ }^{[39]}$ reported that NDI significantly decreased after they conducted intervention programs, including scapular exercise for three months, to reposition the scapula that was not well aligned, which is consistent with the results of this study. In addition, many studies reported that applying therapeutic exercises to FHP decreased pain. ${ }^{[17,37,40]}$ The results of this study confirm that a combination of SSE and TEE, not directly applied to the neck, is effective in reducing pain.

It is difficult to generalize the results of this study due to its small sample size and the nature of participants with certain jobs. In addition, the 
intervention period was relatively short (6 weeks); therefore, the long-term effect of the intervention remains unknown. Lastly, the respective effects of SSE and thoracic spinal extension exercise were not identified. Therefore, in future studies, it is necessary to investigate how long the effect of the intervention would last in larger samples with various occupations.

In conclusion, a combination of SSE and TEE, not directly applied, exercises to the cervical spine is effective in improving the posture, respiration, neck pain, and disability in office workers with FHP. Therefore, it can be an option for many different interventions to reduce and prevent the symptoms of office workers with FHP. In particular, in cases in whom an exercise cannot be directly applied to the cervical spine, it is recommended as an effective method. Nonetheless, further large-scale, long-term studies are needed to confirm these findings.

\section{Declaration of conflicting interests}

The authors declared no conflicts of interest with respect to the authorship and/or publication of this article.

\section{Funding}

This research was supported by a Daegu University Research Grant in 2018.

\section{REFERENCES}

1. Fejer R, Kyvik KO, Hartvigsen J. The prevalence of neck pain in the world population: a systematic critical review of the literature. Eur Spine J 2006;15:834-48.

2. Murray CJ, Atkinson C, Bhalla K, Birbeck G, Burstein R, Chou D, et al. The state of US health, 1990-2010: burden of diseases, injuries, and risk factors. JAMA 2013;310:591-608.

3. Cohen SP. Epidemiology, diagnosis, and treatment of neck pain. Mayo Clin Proc 2015;90:284-99.

4. Nejati P, Lotfian S, Moezy A, Nejati M. The study of correlation between forward head posture and neck pain in Iranian office workers. Int J Occup Med Environ Health 2015;28:295-303.

5. Kanchanomai S, Janwantanakul P, Pensri P, Jiamjarasrangsi W. Prevalence of and factors associated with musculoskeletal symptoms in the spine attributed to computer use in undergraduate students. Work 2012;43:497-506.

6. Grob D, Frauenfelder H, Mannion AF. The association between cervical spine curvature and neck pain. Eur Spine J 2007;16:669-78.

7. Harrison DE, Harrison DD, Betz JJ, Janik TJ, Holland $\mathrm{B}$, Colloca CJ, et al. Increasing the cervical lordosis with chiropractic biophysics seated combined extensioncompression and transverse load cervical traction with cervical manipulation: nonrandomized clinical control trial. J Manipulative Physiol Ther 2003;26:139-51.
8. Lukasiewicz AC, McClure P, Michener L, Pratt N, Sennett B. Comparison of 3-dimensional scapular position and orientation between subjects with and without shoulder impingement. J Orthop Sports Phys Ther 1999;29:574-83.

9. Yoo WG, Yi CH, Kim MH. Effects of a ball-backrest chair on the muscles associated with upper crossed syndrome when working at a VDT. Work 2007;29:239-44.

10. Kotwani S, Bid DN, Ghatamaneni D, Alahmari KA, Ramalingam T, Paul Silvian S. Determining the reliability of craniocervical flexion test in asymptomatic individuals. Hong Kong Physiother J 2018;38:33-40.

11. Kapreli E, Vourazanis E, Billis E, Oldham JA, Strimpakos N. Respiratory dysfunction in chronic neck pain patients. A pilot study. Cephalalgia 2009;29:701-10.

12. Kapreli E, Vourazanis E, Strimpakos N. Neck pain causes respiratory dysfunction. Med Hypotheses 2008;70:1009-13.

13. Dimitriadis Z, Kapreli E, Strimpakos N, Oldham J. Respiratory weakness in patients with chronic neck pain. Man Ther 2013;18:248-53.

14. Perri, MA, Halford E. Pain and faulty breathing: A pilot study. Journal of Bodywork and Movement Therapies 2004;8:297-306.

15. Sheikhhoseini R, Shahrbanian S, Sayyadi P, O'Sullivan K. Effectiveness of Therapeutic Exercise on Forward Head Posture: A Systematic Review and Meta-analysis. J Manipulative Physiol Ther 2018;41:530-9.

16. Ruivo RM, Pezarat-Correia P, Carita AI. Effects of a Resistance and Stretching Training Program on Forward Head and Protracted Shoulder Posture in Adolescents. J Manipulative Physiol Ther 2017;40:1-10.

17. Gupta BD, Aggarwal S, Gupta B, Gupta M, Gupta N. Effect of Deep Cervical Flexor Training vs. Conventional Isometric Training on Forward Head Posture, Pain, Neck Disability Index In Dentists Suffering from Chronic Neck Pain. J Clin Diagn Res 2013;7:2261-4.

18. Ghamkhar L, Arab AM, Nourbakhsh MR, Kahlaee AH, Zolfaghari R. Examination of Regional Interdependence Theory in Chronic Neck Pain: Interpretations from Correlation of Strength Measures in Cervical and Pain-Free Regions. Pain Med 2020;21:e182-e90.

19. Sueki DG, Cleland JA, Wainner RS. A regional interdependence model of musculoskeletal dysfunction: research, mechanisms, and clinical implications. J Man Manip Ther 2013;21:90-102.

20. Cools AM, Dewitte V, Lanszweert F, Notebaert D, Roets A, Soetens B, et al. Rehabilitation of scapular muscle balance: which exercises to prescribe? Am J Sports Med 2007;35:1744-51.

21. Kanlayanaphotporn R, Chiradejnant A, Vachalathiti R. The immediate effects of mobilization technique on pain and range of motion in patients presenting with unilateral neck pain: a randomized controlled trial. Arch Phys Med Rehabil 2009;90:187-92.

22. Dunning JR, Cleland JA, Waldrop MA, Arnot CF, Young IA, Turner M, et al. Upper cervical and upper thoracic thrust manipulation versus nonthrust mobilization in patients with mechanical neck pain: a multicenter randomized clinical trial. J Orthop Sports Phys Ther 2012;42:5-18. 
23. Yoo WG. Effect of thoracic stretching, thoracic extension exercise and exercises for cervical and scapular posture on thoracic kyphosis angle and upper thoracic pain. J Phys Ther Sci 2013;25:1509-10.

24. Salahzadeh Z, Maroufi N, Ahmadi A, Behtash H, Razmjoo A, Gohari M, Parnianpour M. Assessment of forward head posture in females: observational and photogrammetry methods. J Back Musculoskelet Rehabil 2014;27:131-9.

25. Lee MY, Lee HY, Yong MS. Characteristics of cervical position sense in subjects with forward head posture. J Phys Ther Sci 2014;26:1741-3.

26. Kang JI, Choi HH, Jeong DK, Choi H, Moon YJ, Park JS. Effect of scapular stabilization exercise on neck alignment and muscle activity in patients with forward head posture. J Phys Ther Sci 2018;30:804-8.

27. Jull GA, Falla D, Vicenzino B, Hodges PW. The effect of therapeutic exercise on activation of the deep cervical flexor muscles in people with chronic neck pain. Man Ther 2009;14:696-701.

28. Harman, K, Hubley-Kozey CL, Butler H. Effectiveness of an exercise program to improve forward head posture in normal adults: A randomized, controlled 10-week trial. Journal of Manual \& Manipulative Therapy 2005;13:163-76.

29. Nemmers TM, Miller JW, Hartman MD. Variability of the forward head posture in healthy community-dwelling older women. J Geriatr Phys Ther 2009;32:10-4.

30. Bijur PE, Silver W, Gallagher EJ. Reliability of the visual analog scale for measurement of acute pain. Acad Emerg Med 2001;8:1153-7.

31. Ludvigsson ML, Peterson G, O’Leary S, Dedering $\AA$, Peolsson A. The effect of neck-specific exercise with, or without a behavioral approach, on pain, disability, and self-efficacy in chronic whiplash-associated disorders: a randomized clinical trial. Clin J Pain 2015;31:294-303.
32. Alpayci M, İler S. Isometric exercise for the cervical extensors can help restore physiological lordosis and reduce neck pain: A randomized controlled trial. Am J Phys Med Rehabil 2017;96:621-6.

33. Babski-Reeves, K, Stanfield J, Hughes, L. Assessment of video display workstation set up on risk factors associated with the development of low back and neck discomfort. International Journal of Industrial Ergonomics. 2005;35:593-604.

34. Hickey ER, Rondeau MJ, Corrente JR, Abysalh J, Seymour CJ. Reliability of the Cervical Range of Motion (CROM) Device and Plumb-Line Techniques in Measuring Resting Head Posture (RHP), Journal of Manual \& Manipulative Therapy 2000;8:10-7.

35. Lynch SS, Thigpen CA, Mihalik JP, Prentice WE, Padua D. The effects of an exercise intervention on forward head and rounded shoulder postures in elite swimmers. Br J Sports Med 2010;44:376-81.

36. Shiravi S, Letafatkar A, Bertozzi L, Pillastrini P, Khaleghi Tazji M. Efficacy of abdominal control feedback and scapula stabilization exercises in participants with forward head, round shoulder postures and neck movement impairment. Sports Health 2019;11:272-9.

37. Cho J, Lee E, Lee S. Upper thoracic spine mobilization and mobility exercise versus upper cervical spine mobilization and stabilization exercise in individuals with forward head posture: a randomized clinical trial. BMC Musculoskelet Disord 2017;18:525.

38. Shim JH, Oh DW, Lee GW. The effects of thoracic flexibility exercise on vital capacity and chest expansion in patients with idiopathic scoliosis. Phys Ther Korea 2002;9:145-56.

39. McDonnell GV, Bell KE, Hawkins SA. A pain in the neck. Postgrad Med J 2000;76:57-60.

40. Lee SM, Lee CH, O’Sullivan D, Jung JH, Park JJ. Clinical effectiveness of a Pilates treatment for forward head posture. J Phys Ther Sci 2016;28:2009-13. 